\title{
SISTEM: Increasing High School Students' Engineering Career Awareness (Evaluation, Diversity)
}

\section{Dr. Schetema Nealy, University of Nevada, Las Vegas \\ Dr. Erica J. Marti, University of Nevada, Las Vegas}

Erica Marti completed her PhD in Civil and Environmental Engineering at the University of Nevada, Las Vegas (UNLV). She holds a Master of Science in Engineering and Master of Education from UNLV and a Bachelor of Science in chemistry from the University of Illinois at Urbana-Champaign. Prior to graduate studies, Erica joined Teach for America and taught high school chemistry in Las Vegas. While her primary research involves water and wastewater, she has strong interests in engineering education research, teacher professional development, and secondary STEM education. 


\title{
SISTEM: Increasing High School Students’ Engineering Career
}

\author{
Awareness (Evaluation, Diversity)
}

\begin{abstract}
Student Interactions with Science, Technology, Engineering and Math (SISTEM) is a program designed to make high school students aware of the variety of careers in science, technology, engineering, and mathematics (STEM). Furthermore, the SISTEM program sought to increase excitement and interest in STEM fields. Four sessions of SISTEM were conducted in 2016-2018 with over 130 high school student participants (grades 9-12) from multiple schools in a metropolitan area. Over 50\% were from underrepresented minorities in STEM and $78 \%$ of participants were female. Each session consisted of two STEM presentations held one evening a week for five weeks, which amounted to the same group of 30-40 students hearing about ten STEM careers. Professionals in various STEM fields presented about their career, as well as their educational and life journey. The STEM professionals who presented were specifically asked to talk about obstacles they faced in their education and career paths, and how they persisted despite these challenges. In addition, most of the professionals included a hands-on activity to engage the students in an aspect of that STEM career. The STEM career sessions were supplemented with short presentations about college resources, information on research opportunities, and a tour of research laboratories.
\end{abstract}

Participants completed pre- and post-surveys on STEM interest and career awareness. The postsurvey also included questions about the speakers and program logistics. Participants had high interest levels in STEM before participating in the program. The highest increases in participant knowledge after SISTEM were in gaining exposure to STEM professionals and increasing preemployment skills related to STEM careers.

In addition to the program evaluation, some students opted to participate in a research study on grit and learning mindset, which are associated with successful students. Past research has shown that grit scores are good predictors of grade point average, performance, and achievement. Similarly, a student's learning belief - growth or fixed mindset - has been shown to correlate to academic achievement. The authors were interested to see if either grit or learning mindset could be changed in a short period of time within an informal learning situation (i.e., SISTEM). For the research study, students answered the same set of questions before and after SISTEM. The survey combined previously developed instruments for grit. After checking data for internal consistency, the data were analyzed using paired t-tests and multivariate analysis. Findings include a statistically significant increase in grit for female participants, yet no statistically significant change in the learning mindset of the participants. 
Keywords: engineering pathways, career paths, STEM, underrepresented students, grit, growth mindset, high school

\section{Introduction}

The need for a more diverse STEM workforce has been established as a national concern for the United States [1], [2]. An effort toward making science accessible to all students needs to be made in order to increase the representation of underrepresented groups in science fields of study [3]. With the implementation of the Next Generation Science Standards, there is also a push to increase the visibility and understanding of engineering at the K-12 level in order to prepare students for $21^{\text {st }}$ century jobs [4], [5].

One major roadblock for young students to learn about STEM careers is the lack of exposure. Both in the United States and the United Kingdom, studies have shown that most students [6], [9] and teachers [10] are not knowledgeable about STEM careers. In one study [6], students indicated that family and teachers, followed by friends, are the most common places they turn to for career advice. For students whose parents are not in STEM careers or who are not knowledgeable about STEM careers, this puts them at a great disadvantage because there are few people they can turn to in order to get advice about STEM careers.

Student Interactions with Science, Technology, Engineering and Math (SISTEM) is a program designed to address the knowledge gap identified above. The goal of SISTEM is to increase awareness of and interest in STEM careers among high school students. This paper describes the program and reports on its successes in achieving program objectives, as well as a research objective described below. 
Acquiring knowledge, skills, and habits of mind is part of what is required to be on a successful pathway to a STEM career [7]. Grit and growth mindset are two habits of minds. Duckworth (2007) describes grit as a perseverance and a passion for long term goals [8]. Grittier individuals work longer and harder toward success [11]. Learning mindset is divided into fixed and growth viewpoints. Those with a fixed mindset see their personality traits as static and incapable of changing, so they tend to avoid challenges and give up when faced with obstacles [7]. Conversely, those with a growth mindset welcome challenges and persevere when faced with obstacles. Thus, acquiring the constructs of grit and growth mindset as habits of mind may contribute to a student's successful pathway to a STEM career.

There is a body of literature which focuses on assessing STEM outreach programs for their effectiveness toward building interest and participation in STEM fields of study. However, there is a need for more literature which assesses STEM outreach programs by analyzing the programs' effectiveness toward building the participants' habits of mind, such as grit and growth mindset. This study examines how the SISTEM experience affects the grit and growth mindset of high school participants.

\section{Program Objectives}

To meet the overall goal of increasing awareness and interest in STEM careers, specific objectives were identified (Table 1) and evaluated as part of the program assessment.

Table 1. SISTEM program objectives. 
1. Increase student knowledge of STEM topics.

2. Increase student awareness of STEM opportunities and careers for high school students.

3. Increase student knowledge of opportunities for students to pursue a career in a STEM field.

4. Increase student knowledge of opportunities to pursue a post-secondary degree in a STEM field.

5. Increase student knowledge of how to increase pre-employment skills related to STEM careers.

6. Increase student knowledge of opportunities to gain direct exposure to professionals in STEM-related careers.

7. Increase student motivation to follow through with next steps to fulfill STEM career decisions.

8. Increase student interest in working on STEM projects in the future.

9. Increase student commitment to continue studies and/or professional development in a STEM area.

\section{Description of Program}

SISTEM was a grant-funded program that offered high school participants the opportunity to learn about a variety of STEM careers. The program took place at a university in the southwest region of the United States. SISTEM met once per week for five consecutive weeks. All of the participants arrived in the evening, ate a complimentary dinner, and then attended a brief information session or "lightning" talk on a college resource before the symposia (Table 2). At each SISTEM meeting, the participants attended two separate symposia presented by two local STEM professionals (Table 3). Particular attention was paid to selecting a diverse group of STEM professionals from different fields (Tables 4 and 5). Each symposium gave the participants information about the STEM professional's background and education, their personal experiences associated with earning their STEM degrees, and information about how 
their STEM degrees are related to their current position of their careers. In addition, each STEM professional included an interactive, hands-on STEM activity in their presentation that demonstrated a part of the STEM professional's job responsibilities.

Table 2. Example topics for college resource "lightning" talks.

\begin{tabular}{|l|l|l|}
\hline Financial Aid & Honors College & Office of Admissions \\
\hline Advising and Career Center & Office of Undergraduate Research & Student Organizations \\
\hline Multicultural Program & Statewide STEM Resources & Fraternity \& Sorority Life \\
\hline
\end{tabular}

Table 3. STEM disciplines for each of the four semesters of SISTEM.

\begin{tabular}{|l|l|}
\hline \multicolumn{1}{|c|}{ Fall 2016 } & \multicolumn{1}{c|}{ Spring 2017 } \\
\hline Biochemistry & Engineering Entrepreneurship \\
\hline Geographic Information System & Electrical and Computer Engineering \\
\hline Technology / Internet of Things & Mechanical Engineering: Drones \\
\hline Mathematics: Gait \& Video Analysis & Forensic Science \\
\hline Geoscience and Aerospace Engineering & Transportation Engineering \\
\hline Mechanical Engineering: Solar Energy & Biomedical Research \\
\hline Microbiology & Entertainment Engineering \\
\hline Civil Engineering: Construction & Mechanical Engineering: Solar Energy \\
\hline Anthropology / Microbiome & Biochemistry \\
\hline Environmental Engineering & Aquatic Ecology \\
\hline \multicolumn{1}{|c|}{ Fall 2017 } & Spring 2018 \\
\hline Civil Engineering: Water Distribution & Mechanical Engineering: Robotics \\
\hline Civil Engineering: Geological & Biomedical Science \\
\hline Mathematics: Structure & STEration at Museums \\
\hline
\end{tabular}




\begin{tabular}{|l|l|}
\hline Zoology & Mathematics: Rules and Reasoning \\
\hline Archaeology & Environmental Science \\
\hline Paleoanthropology & Entertainment Engineering and Design \\
\hline Chemistry & Mechanical Engineering: Solar Energy \\
\hline Radiation Science and Engineering & Renewable Energy \\
\hline Forensic Science & Civil Engineering: Planning \\
\hline Entertainment Engineering and Design & Engineering Entrepreneurship \\
\hline
\end{tabular}

Table 4. Speaker composition by gender during the four semesters of SISTEM.

\begin{tabular}{|l|c|c|c|c|}
\hline & Fall 2016 & Spring 2017 & Fall 2017 & Spring 2018 \\
\hline Number of women presenters & 4 & 6 & 4 & 7 \\
\hline Number of men presenters & 6 & 4 & 6 & 3 \\
\hline Total presenters & 10 & 10 & 10 & 10 \\
\hline
\end{tabular}

Table 5. Speaker composition by discipline during the four semesters of SISTEM. One speaker was classified as both science and engineering due to discussion of two different careers.

\begin{tabular}{|l|c|c|c|c|}
\hline & Fall 2016 & Spring 2017 & Fall 2017 & Spring 2018 \\
\hline Engineering & 3.5 & 4 & 4 & 5 \\
\hline Math & 1 & 0 & 1 & 1 \\
\hline Science & 3.5 & 4 & 5 & 3 \\
\hline Technology & 2 & 2 & 0 & 1 \\
\hline Total presentations & 10 & 10 & 10 & 10 \\
\hline
\end{tabular}

\section{Schedule}

Each program lasted two hours on a weekday evening (Table 6). The start time of 5:30 pm was selected to allow students to participate in afterschool activities, as well as allow parents time to drop off their children after their normal work day.

Table 6. Typical evening schedule for SISTEM. 


\begin{tabular}{|l|l|l|}
\hline Time & Activity & Details \\
\hline 4:00-5:00 pm & Set up & $\begin{array}{l}\text { Put out signs, set up registration table } \\
\text { Help vendor set up dinner }\end{array}$ \\
\hline 5:00-5:30 pm & Arrival / Sign-in & $\begin{array}{l}\text { Students arrive and sign in at registration table. } \\
\text { Students complete survey or icebreaker activity. }\end{array}$ \\
\hline 5:30-5:50 pm & Dinner & $\begin{array}{l}\text { Students have dinner; socialize with other students } \\
\text { and speakers }\end{array}$ \\
\hline 5:50-5:55 pm & Lightning Talk & Short presentation on a campus resource or activity \\
\hline 5:55-6:00 pm & Move to classrooms & Transition to speaker presentations \\
\hline 6:00-6:40 pm & Presentation 1 & $\begin{array}{l}\text { 40 minutes; Speaker presentation, activity and } \\
\text { questions }\end{array}$ \\
\hline 6:40-6:50 pm & Break & Students switch classrooms / bathroom break \\
\hline 6:50-7:30 pm & Presentation 2 & $\begin{array}{l}\text { 40 minutes; Speaker presentation, activity and } \\
\text { questions }\end{array}$ \\
\hline 7:30 pm & Conclusion & Collect name badges and raffle tickets \\
\hline
\end{tabular}

\section{Program Evaluation and Results}

Pre- and post-surveys were completed by participants to assess if program objectives were met. Participants were asked to rate their agreement on a 5-point Likert scale (strongly agree to strongly disagree) on items that corresponded directly to program objectives (Table 1).

Although scores for all objectives were initially high (i.e., strongly agree, agree, neither agree/disagree), indicating participants were interested in STEM, the responses were higher on the post-survey. Thus, participants showed an increased interest in STEM and knowledge of STEM careers after the program. The highest increases in participant knowledge after SISTEM 
were in gaining exposure to STEM professionals and increasing pre-employment skills related to STEM careers (Objectives 5 and 6).

An inherent challenge for the program is continued interaction for the participants with STEM professionals. While some participants repeated the program in subsequent semesters, many participants attended only once. It is unknown if participant interest in STEM persisted after the program. Therefore, program staff is looking at options to stay connected with participants and inform them of other STEM activities and opportunities.

\section{Research Methods}

Sample Population

The participants of this study included high school students who expressed having an interest in STEM. Of the 136 students who participated in SISTEM, 74 completed at least one of the preand post-test surveys used in this study. The survey sample included participants $(n=54)$ who completed both the pre-test and the post-test.

\section{Data Collection - Surveys}

A STEM Attitudes and Beliefs survey was administered in this study. This survey instrument was a compilation of the short grit survey and growth mindset survey. The Short Grit Survey Scale, developed and validated by Duckworth et al. (2009), is an 8-item self-report scale designed to elicit participants' perceptions of their behaviors related to setting and pursuing achievement goals [11], [13], [14]. The growth mindset survey is an 8-item self-report scale designed to understand participants' attitudes toward their ability to change their intelligence 
levels. This short growth mindset survey was developed by Flores et al. (2006) and is based on the survey originally developed and validated by Dweck (2006) [12], [15].

To measure the causal effect of their participation in the SISTEM program, the participants' grit, and growth mindset were measured using a behavior analysis design in which the pre-test survey and a post-test survey were identical. The participants were asked to voluntarily and anonymously complete the Likert scale survey (i.e., the STEM Attitudes and Beliefs test), before the first SISTEM meeting in week one, and then to complete the same survey after the last SISTEM meeting in week five. In addition to the STEM Attitudes and Beliefs survey, students reported demographic information including grade level, gender, and ethnicity. One student declined to answer the question about gender.

\section{Data Analysis}

To determine statistical significance, the data were analyzed using SPSS. The tests run were paired samples t-test followed by multivariate analysis. Only the surveys of students who completed both the pre-test and the post-test were used as data for this study. Therefore, some students' surveys were not used because either their pre-test or post-test was missing.

\section{Research Study Results}

Both constructs of grit and growth mindset levels were analyzed, comparing pre-tests to posttests, for the groups of students listed in Table 7.

Table 7. Sample groups analyzed for grit and growth mindset levels. 


\begin{tabular}{|l|l|l|}
\hline Test & Student Group & Number of Students (n) \\
\hline 1 & All groups & 54 \\
\hline 2 & African-American & 3 \\
\hline 3 & Asian & 10 \\
\hline 4 & Caucasian/White & 17 \\
\hline 5 & Hispanic/Latino & 20 \\
\hline 6 & Male & 24 \\
\hline 7 & Female & 29 \\
\hline
\end{tabular}

The Pearson correlation test resulted in evidence which supports the presence of test-retest reliability. While no statistically significant results were found from tests \#1-6 above, a significant difference $(\mathrm{p}<0.034)$ for female students' level of grit $(\# 7)$ was discovered. In other words, female students demonstrated an increased level of grit as a result of their participation in the SISTEM program. The interpretation of this is that the SISTEM program had a positive effect on the grit level of female participants.

\section{Discussion and Limitations}

Due to the limitations of a short period of time (one day a week for five weeks) that the SISTEM program ran and having a small sample population which completed the surveys, it is not surprising that statistically significant differences were not found across most of the groups. A change in grit and in growth mindset can take a much larger amount of time to emerge. 
However, this does not nullify the statistically significant change which was detected in this study, specifically the positive correlation between the female students' grit levels and their participation in the SISTEM program. This finding aligns with what has been found previously; McClary et al. (2018) also found a difference in grit among high school students who attended a 2-week STEM program [16]. In that study, the grit and growth mindset levels of 47 high school students of various backgrounds were surveyed. Both grit and growth mindset increased after the STEM program; however, the increase was not statistically significant [16]. These results speak to the possibility of changing students' grit levels in a short time frame. However, more research must be done with a larger group of student participants in order to be able to generalize this result.

Specific program components may have contributed to increased grit for female participants: 1) the high number of women STEM presenters and 2) inclusion of obstacles faced by STEM professionals in their education and career paths, and how they persisted despite these challenges. This is an area of study for future SISTEM programs.

The results of this study suggest that researchers could aim their research foci on how to retain the STEM interests of female students using STEM outreach programs and experiences, especially at the middle school level when most students tend to lose their interest in STEM [17]. With this study showing promise toward increasing the grit level of high school students who participated in a STEM outreach program, it stands to reason that STEM outreach programs can be helpful in strengthening grit in younger female students as grit is best when developed at a younger age [18]. 


\section{Acknowledgments}

Opinions, findings, conclusions or recommendations expressed in this material are those of the author(s) and do not necessarily reflect the views of the National Science Foundation. This material is based upon work that was partly funded by the National Science Foundation under grant number IIA1301726.

\section{References}

[1] Kuenzi, J. J. (2008). Science, technology, engineering, and mathematics (STEM) education: Background, federal policy, and legislative action. Washington, DC: Congressional Research Service.

[2] National Academy of Sciences. (2011). Expanding Underrepresented Minority Participation: America's Science and Technology Talent at the Crossroads. (Committee on Underrepresented Groups and the Expansion of the Science and Engineering Workforce Pipeline). Washington, D.C: National Academies Press.

[3] Stake, J. E., Mares, K. R. (2001). Science enrichment programs for gifted high school girls and boys: Predictors of program impact on science confidence and motivation. Journal of Research in Science Teaching, 38(10), 1065 - 1088.

[4] NGSS Lead States. (2013). Next Generation Science Standards: For States, By States. Washington, DC: The National Academies Press.

[5] National Research Council. (2012). A framework for K-12 science education: Practices, crosscutting concepts, and core ideas. National Academies Press. 
[6] Wellcome Trust. (2013). Wellcome Trust Monitor, Wave 2. Retrieved from https://wellcome.ac.uk/sites/default/files/monitor-wave2-full-wellcome-may13.pdf

[7] Zephirin, T., Tolbert, D., Dickerson, D., \& Solis, F. (2014). Development of non-cognitive skills in minority engineering outreach programs. In 2014 IEEE Frontiers in Education Conference (FIE) Proceedings (pp. 1-4). IEEE.

[8] Duckworth, A. L., Peterson, C., Matthews, M. D., \& Kelly, D. R. (2007). Grit: Perseverance and passion for long-term goals. Journal of Personality and Social Psychology, 92(6), 1087-1101. doi:10.1037/0022-3514.92.6.1087

[9] Tsupros, N., Kohler, R., \& Hallinen, J. (2009). STEM education: A project to identify the missing components. Intermediate Unit 1, Center for STEM Education and Leonard Gelfand Center for Service Learning and Outreach. Retrieved from https://www.cmu.edu/gelfand/documents/stem-survey-report-cmu-iu1.pdf

[10] University of the Sciences. (2012). A survey of high school students' attitudes towards careers in healthcare and science. Survey conducted by Harris Interactive, April 2012. www.usciences.edu/newsEvents/newsDetails.aspx?Channel=\%2FChannels\%2FAdmissio ns\%2FAdmissions+Content $\&$ WorkflowItemID=61a1 f646-130e-4372-afe0a60e61b9a359

[11] Bazelais, P., Lemay, D. J., Doleck, T. (2016). How does grit impact college students; academic achievement in science? European Journal of Science and Mathematics Education. 4(1), 33-43.

[12] Dweck, C.S., (2006). Mindset: The New Psychology of Success. New York: Random House, Inc. 
[13] Duckworth, A. L., Peterson, C., Matthews, M. D., \& Kelly, D. R. (2007). Grit: perseverance and passion for long-term goals. Journal of personality and social psychology, 92(6), 1087.

[14] Duckworth, A., \& Quinn, P. (2009). Development and Validation of the Short Grit Scale (Grit-S). Journal Of Personality Assessment, 91(2), 166-174.

doi: $10.1080 / 00223890802634290$

[15] Flores, D., Lemons, A., \& McTernan, H. (2011). The Correlation between Student Growth Mindset and Conceptual Development in Physic (Action Research Thesis). Retrieved from http://modeling.asu.edu/modeling/Mindset\&Physics-McT,L,F.pdf.

[16] McClary, T., Zeiber, J. A., Sullivan, P., \& Stochaj, S. (2018). Using Multi-Disciplinary Design Challenges to Enhance Self-Efficacy within a Summer STEM Outreach Program. Proceedings of the 2018 ASEE Gulf-Southwest Section Annual Conference.

[17] National Research Council. (2009). Learning science in informal environments: People, places, and pursuits (P. Bell, B. Lewenstein, A. W. Shouse, \& M A. Feder, Eds.). Washington, DC: National Academies Press.

[18] Dweck, C. S., Walton, G. M., \& Cohen, G. L. (2014). Academic Tenacity: Mindsets and Skills that Promote Long-Term Learning. Seattle, WA: Bill \& Melinda Gates Foundation. 